\title{
Factors that motivate people to undergo cosmetic surgery
}

\author{
Adrian Furnham DPhil DSc, James Levitas BSc(Hons)
}

A Furnham, J Levitas. Factors that motivate people to undergo cosmetic surgery. Can J Plast Surg 2012;20(4):e47-e50.

A sample of 204 British participants completed a questionnaire that assessed their attitude toward cosmetic surgery as well as measures of selfesteem, life satisfaction, self-rated physical attractiveness, religiosity and media consumption. Two factors emerged from a factor analysis of their attitudes toward surgery: likelihood to undergo, and benefits of undergoing, cosmetic surgery. Females with low self-esteem, low life satisfaction, low self-rated attractiveness and little religious beliefs who were heavy television watchers reported a greater likelihood of undergoing cosmetic surgery. Stepwise regression analysis with the two attitude factors as criterion variables showed two major predictors for likelihood: religiousness and low self-esteem, and four major predictors for benefit: religousness, media consumption, life satisfaction and sex. The role of religion is considered in this context.

Key Words: Attractiveness; Cosmetic surgery; Sex differences

$\mathrm{T}$ he role of attractiveness in Western society has been extensively explored by evolutionary and social psychologists (1-3). A metaanalysis of more than 900 studies by Langlois et al (4) provides further support that people are treated differently based on how physically attractive they are perceived to be. Given the influence that physical attractiveness has in our everyday lives, it is perhaps not surprising that people seek a means to alter their appearance to conform to societal ideals of attractiveness. The present study investigated attitudes toward cosmetic surgery by replicating and extending three studies in this area (5-7). The focus of the present study was on how media consumption and religious beliefs, in addition to self-esteem and life satisfaction, influence attitudes to cosmetic surgery.

Cosmetic surgery is concerned with the "maintenance, restoration or enhancement of one's physical appearance through surgical and medical techniques" (7). The American Society for Aesthetic Plastic Surgery reported an increase of $446 \%$ in cosmetic procedures since 1997 and an overall increase of $8 \%$ in 2007, with a $17 \%$ increase in men undertaking cosmetic surgery (8). This increase is similar in the United Kingdom. The British Association of Plastic Surgeons recorded a $35 \%$ increase in procedures performed by its members from 2004 to 2005 (9). With the increased prevalence, accessibility and evolution of cosmetic surgery in Western society, it is becoming increasingly relevant to explore the various internal and external factors that motivate people to undergo cosmetic surgery. Sarwer et al (10) attribute this recent increase to the availability of plastic surgeons, the influence of the media, evolutionary interests and personal factors relating to the patient. The technological advances in cosmetic surgery have made it safer and less invasive, with a faster recovery time, as well as lowering the cost of procedures. Thus, people have become less anxious, and more willing to consider and accept cosmetic surgery as a possible option for altering their physical appearance (11).

The decision to seek out plastic surgery has recently attracted a significant amount of attention (12-14). Studies have focused on evolutionary, psychosocial and health behavioural covariates of those who have undergone cosmetic surgery (15), as well as more attitudinal and

\section{Les facteurs qui motivent les gens à subir une chirurgie esthétique}

Un échantillon de 204 participants britannique ont rempli un questionnaire qui évaluait leur attitude envers la chirurgie plastique et contenait des mesures d'estime de soi, de satisfaction envers la vie, d'attirance physique autoévaluée, de religiosité et de consommation des médias. Deux facteurs ont émergé d'une analyse factorielle de leurs attitudes envers la chirurgie : la probabilité et les avantages de subir une chirurgie. Les femmes ayant une faible estime de soi, une satisfaction peu élevée envers la vie, une faible attirance physique autoévaluée et peu de convictions religieuses qui regardaient beaucoup la télévision étaient les plus susceptibles de subir une chirurgie esthétique. Une analyse de régression échelonnée faisant appel aux deux facteurs d'attitude comme variables de critère a révélé deux grands prédicteurs de probabilité : la religiosité et la faible estime de soi, et quatre grands prédicteurs d'avantages : la religiosité, la consommation des médias, la satisfaction envers la vie et l'activité sexuelle. Le rôle de la religion est examiné dans ce contexte.

belief system factors such as life satisfaction, self-esteem and body image (16). A comprehensive review by Ching et al (17) found a patient's body image and perceived quality of life to be the strongest and most consistent determinants of aesthetic surgery outcomes. The present study focused on two factors previously disregarded in this literature: media consumption and religious beliefs.

Markey and Markey (18) recently examined young American women's interest in obtaining cosmetic surgery. They found that all four factors they investigated - namely, body dissatisfaction, physical appearance, teasing (being teased about 11 different body parts) and media influence (feeling pressured to appear like people in the media) - were related to the desire to have cosmetic surgery. The best predictor of their interest in obtaining cosmetic surgery was body dissatisfaction, which has been investigated extensively.

The majority of studies exploring the reasons one may have for undertaking cosmetic surgery have focused on patient samples. There is a noticeable lack of research focusing on nonpatient samples. Delinsky (13) found that media exposure and vicarious experience predicted a greater likelihood of undergoing cosmetic surgery. Similarly, Brown et al (5) found that vicarious experience of cosmetic surgery increased the likelihood of undergoing cosmetic surgery for women. Their results also suggested that women are more likely to undergo cosmetic surgery than men, and that older men report less desire to undergo cosmetic surgery than younger men. Furthermore, contrary to Delinsky's findings, they found that media exposure did not influence the likelihood of undergoing cosmetic surgery for either sex. They accounted for this finding by suggesting that the saturation of media sources with cosmetic surgery messages has caused awareness to reach a peak (5). Thus, they suggest that the effect of media influence is no longer as pronounced as it once was. This finding, however, needs to be replicated in a different culture.

Sarwer et al (10) proposed that the growing awareness of this beauty bias is partly responsible for the increased number of people altering their appearance through cosmetic procedures. This awareness may cause some individuals to attribute their low life satisfaction to

University College London, London, United Kingdom

Correspondence: Dr Adrian Furnham, University College of London, Main Campus, Gower Street, London WC1E 6BT, United Kingdom.

Telephone 44-20-7679-2000, e-mail a.furnham@ucl.ac.uk 
their physical appearance and seek cosmetic alteration as a consequence. Related to life satisfaction is self-esteem, which previous studies have shown to be negatively associated with the likelihood of having cosmetic surgery (7). Swami et al (7) also showed a strong correlation with participants' self-rated attractiveness and self-esteem. The trait variable of openness was consistently negatively associated with acceptance of cosmetic surgery.

The increasing number of television programmes concerning cosmetic surgery, both fact and fiction, has increased public awareness of the benefits it can offer and has mainstreamed society's awareness of cosmetic procedures (19). Crockett et al (20) showed that cosmetic surgery reality television plays a significant role in cosmetic surgery patient perceptions and decision making. Patients who watched a considerable amount of cosmetic surgery reality shows reported a greater influence from television and media to have cosmetic surgery, compared with low-intensity viewers. High-intensity viewers felt more knowledgeable about cosmetic surgery in general and believed that cosmetic surgery reality television was more similar to real life than did low-intensity viewers.

Research exploring religiosity as a possible factor predicting the likelihood of undergoing cosmetic surgery is sparse. Previous research has shown that religiosity significantly predicts attitudes toward controversial topics in Western society such as abortion (21), genetic screening (22) and euthanasia (23). It is also suggested that religiously conservative individuals of all faiths will have stricter views about 'deception' and sins of vanity. and will be less likely to undergo cosmetic surgery than more liberal or atheist individuals.

The current study aimed to expand the knowledge concerning the spectrum of reasons one may have for undergoing cosmetic surgery. It is an extension and partial replication of the studies by Brown et al (5) and Swami et al (6), focusing on the role of media consumption. Three hypotheses of the current study attempt to replicate previous findings: women will be more likely to have cosmetic surgery than men; lower self-ratings of attractiveness will predict the likelihood of undergoing cosmetic surgery; and lower ratings of self-esteem and life satisfaction will be associated with the likelihood of having cosmetic surgery. Two hypotheses are unique to the study: higher (general) media exposure will predict the likelihood of considering having surgery; and highly religious subjects will be less likely to consider cosmetic surgery than less religious subjects.

\section{METHOD}

\section{Participants}

A total of 204 individuals (90 men, 114 women) ranging in age from 18 to 74 years (mean $[ \pm \mathrm{SD}]$ age $34.73 \pm 16.14$ years) participated in the present study. Most of the participants were of European Caucasian descent $(67.2 \%)$, but other ethnic groups were also represented including Asian (12.3\%) and Afro-Caribbean (2\%). They rated their religiosity on a 7 -point scale $(1=$ not at all; $7=$ very $)$ with a mean of $3.02 \pm 1.72$. The majority of participants were either Christian (38.2\%) or atheist $(38.7 \%)$, although some were Buddhist $(2.9 \%)$ or were of some other religious affiliation $(12.3 \%)$. In terms of marital status, $31.4 \%$ were single, $26 \%$ were dating, $32.4 \%$ were married and $10.3 \%$ were of some other relationship status. Finally, most participants reported never undergoing cosmetic surgery (94.1\%).

\footnotetext{
Measures

Likelihood of having cosmetic surgery scale (5): Questions assessed the participants' acceptance of cosmetic surgery (five items) and their likelihood of undergoing cosmetic surgery (10 items) rated on a fivepoint agree-disagree scale. The two subscales were shown to have high alphas (acceptance: $\alpha=0.90$, and likelihood: $\alpha=0.94$ ).

Self-esteem: The Rosenberg self-esteem scale (24) was used to measure participants' self-worth. The scale consists of 10 items, each of which are rated on a four-point scale ( 1 = stongly disagree, $4=$ strongly agree). The scale had good internal consistency in the current study $(\alpha=0.91)$.
}

Life satisfaction scale (5): This five-item scale measures life satisfaction on a five-point scale ( $1=$ strongly disagree, $5=$ strongly agree $)$. Participants were asked to indicate the extent to which they agreed or disagreed with the various statements (eg, 'In most ways, my life is close to my ideal'). Cronbach's alpha for this scale was 0.84 .

Self-assessed attractiveness (25): This part of the questionnaire required participants to rate their overall physical attractiveness, facial attractiveness, body weight or size and body shape or figure. Participants were provided with a bell-curve graph showing the typical distribution of attractiveness scores $(M=100 \pm 15)$. Thus, 70 was labelled unattractive, 85 low average, 100 average. This had successfully been used in previous studies (7). These four items had high internal consistency $(\alpha=0.95)$.

Media exposure: Media exposure was divided into two sections. First, participants were asked the following questions, which were rated on a five-point scale $(1=$ never, 5 = very often $)$ :

1. How often have you seen advertisements for cosmetic surgery? $(\mathrm{M}=3.61 \pm 1.96)$

2. How often have you read articles or books about cosmetic surgery? $(\mathrm{M}=2.42 \pm 1.53)$

3. How often have you seen television programmes about cosmetic surgery? $(\mathrm{M}=3.11 \pm 1.05)$

4. How often have you heard radio programmes about cosmetic surgery? $(\mathrm{M}=1.74 \pm 0.99)$

5. In general, how often would you say you currently watch television or movies? $(\mathrm{M}=3.97 \pm 1.02)$

6 . In general, how often would you say you currently read magazines? $(\mathrm{M}=3.02 \pm 1.10)$.

These six items had an alpha of 0.64 .

Second, participants were asked about their time spent watching television, reading magazines, listening to podcasts and browsing the Internet, which were rated on a seven-point scale: $1=\geq 4 \mathrm{~h} ; 2=2 \mathrm{~h}$ to $4 \mathrm{~h}, 3=1 \mathrm{~h}$ to $<2 \mathrm{~h} ; 4=\leq 1 \mathrm{~h} ; 5=$ two to three times per week; $6=$ once per week; $7=$ less often. The following mean scores were recorded: television, $\mathrm{M}=3.97 \pm 1.02$; magazines, $\mathrm{M}=3.02 \pm 1.10$; podcasts, $M=1.48 \pm 1.06$; and Internet, $M=5.21 \pm 1.38$. Due to the small number of individuals who reported having heard radio shows on cosmetic surgery, this item was not included in the analysis.

Demographics: Participants were required to provide demographic data including age, sex, ethnicity, religion, marital status, highest educational qualification and number of siblings. They were also asked to state how religious they were using a seven-point scale $(1=$ not at all religious, 7 = very religious).

Personal experience: Participants were asked whether they have ever undergone cosmetic surgery $(1=$ no, 2 = yes $)$ and given the option to state the procedure. Due to only 11 of the 204 participants $(5.4 \%)$ reporting having undergone cosmetic surgery, this item was not included in the analysis.

\section{Procedure}

Once ethical approval had been obtained, participants were approached in various places in the British public (eg, libraries, cafes, train stations, churches, universities) by various researchers experienced in this technique. Individuals were briefed about the nature of the study and then offered the opportunity to participate. They were assured that their data would remain completely anonymous. Once they had provided informed consent, they completed the five-page questionnaire, which took approximately $15 \mathrm{~min}$ to complete. Participants were debriefed after completing the questionnaire. Of those approached, approximately $70 \%$ agreed to participate; the majority of the remainder claimed insufficient time to spare.

\section{Factor analysis}

\section{RESULTS}

A factor analysis with VARIMAX rotation was performed on the 15 -item attitude toward cosmetic surgery scale. The results of the factor 
TABLE 1

Sex differences and factor analytic results for the likelihood questionnaire

\begin{tabular}{|c|c|c|c|c|c|c|}
\hline & \multirow[b]{2}{*}{ Scale } & \multirow{2}{*}{$\begin{array}{c}\text { Male } \\
(n=90)\end{array}$} & \multirow{2}{*}{$\begin{array}{l}\text { Female } \\
(n=114)\end{array}$} & \multirow[b]{2}{*}{ F level } & \multicolumn{2}{|c|}{ Loading } \\
\hline & & & & & F1 & $\mathbf{F 2}$ \\
\hline 1 & It makes sense to have minor cosmetic surgery rather than spending years feeling bad about the way you look. & 4.69 & 3.70 & $12.57^{\star * \star}$ & & 0.83 \\
\hline 2 & Cosmetic surgery is a good thing because it can help people feel better about themselves. & 4.81 & 3.82 & $15.49^{\star \star \star}$ & & 0.84 \\
\hline 4 & People who are very unhappy with their physical appearance should consider cosmetic surgery as one option. & 4.63 & 3.55 & $20.99 * \star \star$ & & 0.84 \\
\hline 5 & If cosmetic surgery can make someone happier with the way they look, then they should try it. & 4.70 & 3.72 & $17.74^{\star \star \star}$ & & 0.82 \\
\hline 6 & If I could have a surgical procedure done for free, I would consider trying cosmetic surgery. & 3.50 & 2.80 & $5.09 *$ & 0.72 & \\
\hline 8 & I have sometimes thought about having cosmetic surgery. & 3.02 & 3.12 & 0.10 & 0.73 & \\
\hline 9 & I would seriously consider having cosmetic surgery if my partner thought it was a good idea. & 2.55 & 2.21 & 1.89 & 0.76 & \\
\hline 10 & I would never have any kind of plastic surgery $(\mathrm{R})$ & 3.68 & 4.25 & 3.04 & & 0.63 \\
\hline 11 & I would think about having cosmetic surgery in order to keep looking young. & 2.81 & 2.70 & 0.17 & 0.73 & \\
\hline 12 & If it would benefit my career, I would think about having plastic surgery. & 3.01 & 2.49 & 4.07 & 0.74 & \\
\hline 13 & I would seriously consider having surgery if I thought my partner would find me more attractive. & 2.72 & 2.06 & $7.70^{* *}$ & 0.78 & \\
\hline 15 & & & & Variance & 34.8 & 31.3 \\
\hline
\end{tabular}

${ }^{* \star *} P<0.001 ;{ }^{* \star P} P<0.01$. Scores were marked on a seven-point scale: Strongly disagree 1234567 Strongly agree. (R) indicates that the scoring for that item was reversed

TABLE 2

Correlations between the major variables

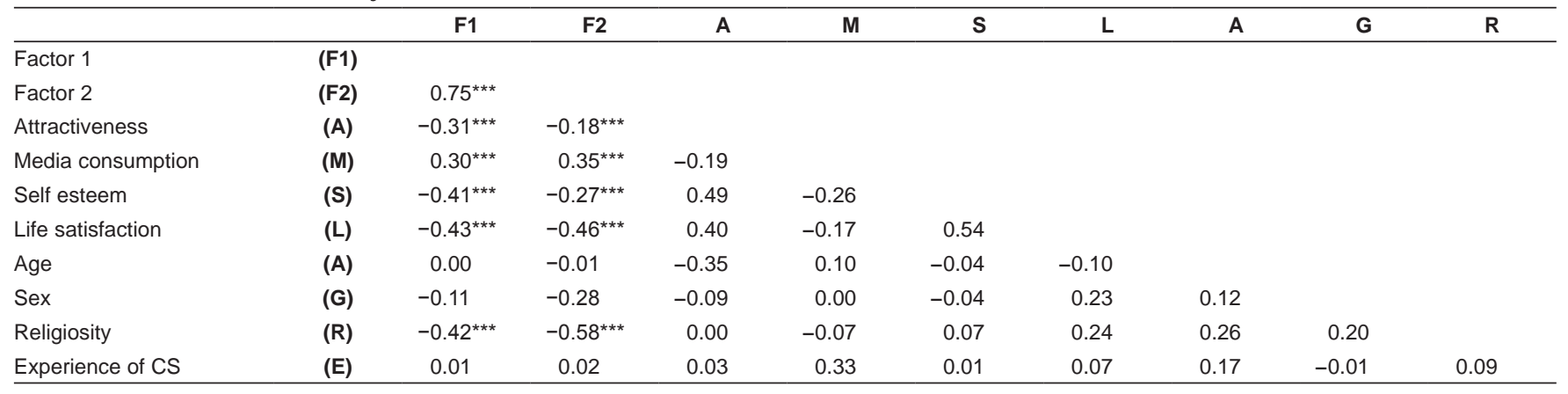

Correlation $r>0.20$; ${ }^{* \star *} P<0.001$. CS Cosmetic surgery

analysis are shown in Table 1. Two factors emerged, labelled: 1) Likelihood of having cosmetic surgery; and 2) Benefits to having cosmetic surgery. The two rotated factors accounted for $66.1 \%$ of the variance, with the first factor accounting for $34.8 \%$ of this variance.

Table 1 also shows the results for the fifteen one-way ANOVAs. Slightly less than one-half showed significant differences, which were all in the same direction (women scored lower than men) and nearly all those items that loaded on the second factor. An ANOVA on the two factor scores showed no significant difference on factor $1(F[1,202]=0.81)$ but a highly significant sex difference on factor $2(F[1,202]=21.42$, $\mathrm{P}<0.001$ ). Women scored higher than men on the second factor.

Table 2 presents the correlations between the different measures with an emphasis on correlates of factors 1 and 2. Correlations were very similar, with the two-factor scores indicating that those with low self-esteem, life satisfaction, self-rated attractiveness and religiousness but high media consumption were more positive toward cosmetic surgery. The table shows that all hypotheses were confirmed.

Two regressions were performed with each factor score as the criterion variable and four sets of predictor variables: Demographic data (sex and age), were entered first, then religiousness, then self-assessment (self-esteem, life satisfaction, attractiveness) and, finally, media consumption. Table 3 shows the results of the final step in the regressions. The first factor was significant and accounted for nearly $20 \%$ of the variance. Demography accounted for no variance, religion $4 \%$ of variance, the self-assessment variables $19 \%$ of variance and media consumption no variance. It showed that nonreligious people with low self-esteem and low perceived self-attractiveness were most willing to undergo cosmetic surgery. The second factor on the benefits of cosmetic surgery showed the predictor variables accounted for $41 \%$ of the variance. The stepwise regression showed that sex accounted for $9 \%$ of the variance, religiousness $32 \%$, life satisfaction 3\% and media consumption $6 \%$. The regression showed that women, with few religious beliefs, low life satisfaction and high overall media consumption, were more accepting of the benefits of cosmetic surgery.

\section{DISCUSSION}

The findings of the current study showed that lower ratings of selfesteem and life satisfaction, increased media exposure to cosmetic surgery via television shows, time spent watching television and religiosity were all significant predictors of the likelihood of undergoing cosmetic surgery. While the correlations between the various measures and the two-factor scores were similar, the regressions showed that different measures predicted the two different factors. The second factor (concerning the benefits of cosmetic surgery) was most strongly predicted by the two unique features of the present study, namely religious beliefs and media consumption.

Both correlations and regressions indicated that, although women were more likely to say they would have surgery, it was the sex difference in perceived benefits (factor 2) that was strongest. The finding that women did not significantly report a greater likelihood of undergoing cosmetic surgery than men is inconsistent with nearly all previous studies $(5,13)$. It was expected that the greater sociocultural 
TABLE 3

\section{Regressional analyses}

\begin{tabular}{|c|c|c|c|c|}
\hline & \multicolumn{2}{|c|}{ Factor 1} & \multicolumn{2}{|c|}{ Factor 2} \\
\hline & Beta & $\mathbf{t}$ & Beta & $\mathbf{t}$ \\
\hline Age & -0.01 & 0.19 & -0.08 & 1.29 \\
\hline Sex & 0.05 & 0.75 & -0.17 & $3.01^{\star \star}$ \\
\hline Religiosity & -0.18 & $2.67^{* *}$ & -0.44 & $7.56^{\star \star \star}$ \\
\hline Self esteem & -0.22 & $2.68^{* *}$ & 0.05 & 0.63 \\
\hline Life satisfaction & -0.08 & 0.97 & -0.22 & $3.13^{* * *}$ \\
\hline Attractiveness & -0.18 & $2.26^{*}$ & -0.09 & 1.28 \\
\hline \multirow[t]{3}{*}{ Media consumption } & 0.06 & 0.85 & 0.26 & $4.67^{* * *}$ \\
\hline & \multicolumn{2}{|c|}{$F(7,196)=7.86^{\star \star \star}$} & \multicolumn{2}{|c|}{$\mathrm{F}(10,196)=21.39^{\star \star *}$} \\
\hline & \multicolumn{2}{|c|}{ Adjusted $\mathrm{R}^{2}=0.19$} & \multicolumn{2}{|c|}{ Adjusted $R^{2}=0.41$} \\
\hline
\end{tabular}

${ }^{*} P<0.05 ;{ }^{*} P<0.01 ;{ }^{* * *} P<0.001$

pressure on women to conform to societal ideals of attractiveness (shown by the prevalence of body image and eating disorders among women) would serve to normalize their pursuit of cosmetic surgery. Studies have also shown real-life biases for attractive women, and discrimination against less attractive women, in several different domains of society $(26,27)$. Considering these findings, the results of the current study are surprising. Cosmetic surgeons, recognizing the increasing number of men undergoing cosmetic surgery in recent years, may no longer be specifically targeting women in their advertising. Therefore, the contemporary view of cosmetic surgery, as propagated by the media, may in fact account for the unusual findings of the current study.

Confirming the results of Brown et al (5), it was found that selfratings of physical attractiveness did have a significant effect on the likelihood of undergoing cosmetic surgery.

The current study showed that self-esteem was negatively associated with the likelihood of undergoing cosmetic surgery. Individuals with low

\section{REFERENCES}

1. Swami V. The influence of body weight and shape in determining female and male physical attractiveness. In: Kindes MV, ed. Body Image: New Research. New York: Nova Biomedical Books, 2006:33-61

2. Swami V. Perceptions of female body weight and shape among indigenous and urban Europeans. Scand J Psychol 2007;48:43-50.

3. Swami V, Furnham A. The Psychology of Physical Attraction. London: Routledge, 2008.

4. Langlois JH, Kalakanis LE, Rubenstein AJ, Larson AD, Hallam MJ, Smoot MT. Maxims and myths of beauty: A meta-analytic and theoretic review. Psychol Bull 2000;126:390-423.

5. Brown A, Furnham A, Glanville L, Swami V. Factors that affect the likelihood of undergoing cosmetic surgery. Aesthet Surg J 2007;27:501-8.

6. Swami V, Arteche A, Chamorro-Premuzic T, et al. Looking good: Factors affecting the likelihood of having cosmetic surgery. Eur J Plast Surg 2008;30:211-18.

7. Swami V, Chamorro-Premuzic T, Bridges S, Furnham A. Acceptance of cosmetic surgery: Personality and individual difference predictors. Body Image 2009;6:7-13.

8. American Society for Aesthetic Plastic Surgery. Quick facts: Highlights of the ASAPS 2007 statistics on cosmetics surgery. <www.surgery.org/media/statistics> (Accessed May 2009).

9. British Association of Aesthetic Plastic Surgeons Annual Audit 2005. <www.baaps.org.uk/about-us/audit/49-over-22000-surgicalprocedures-in-the-uk-in-2005> (Accessed May 2009).

10. Sarwer DB, Magee L, Clark V. What is beauty? Physical appearance and cosmetic medical treatments: Physiological and sociocultural influences. J Cosmet Dermatol 2003;2:29-39.

11. Edmonds A. 'The poor have the right to be beautiful': Cosmetic surgery in neoliberal Brazil. J R Anthropol Inst 2007;13:363-81.

12. Cook S, Rosser R, Salmon P. Is cosmetic surgery an effective psychotherapeutic intervention? A systematic review of the evidence. J Plast Reconstr Aesthet Surg 2006;59:1133-51.

13. Delinsky SS. Cosmetic surgery: A common and accepted form of self improvement? J Appl Soc Psychol 2005;35:2012-28. self-esteem may be more willing to have cosmetic alteration to improve their own self-perceptions, thus boosting their self-esteem, although it is unclear whether that will indeed occur. Individuals with exceptionally low self-esteem and low life satisfaction may, in fact, suffer from depression, meaning that cognitive therapy, as opposed to cosmetic surgery, would be more beneficial. Most plastic surgeons are acutely aware of patients whose hope for the effects of surgery is unrealistic and could, in time, lead both to litigation and increased depression.

The present study particularly examined media exposure/ consumption and attitudes toward cosmetic surgery. The significant effect of media exposure is inconsistent with the study by Brown et al (5), but is consistent with results from other studies $(13,25)$. The current study showed that exposure to media was not related to the first factor (likelihood) but was related to the second factor (benefits) in the regressions. Those who consumed more media believed that cosmetic surgery brought more benefits

The present study also focused on religious beliefs and attitudes toward cosmetic surgery. More religious individuals may be likely to perceive cosmetic alteration as a direct contravention to their religious beliefs. Christian religious authorities strongly advocate the view that people should be less concerned with physical appearance (Philippians 2:3-4) and more concerned with religious issues (Proverbs 31:30) and that true beauty lies within an individual's spirit (1 Peter 3:4) (28). Religiosity is a powerful determinant of an individual's attitude toward several controversial topics $(21-23)$ and therefore it is perhaps not surprising that it determines attitudes toward cosmetic surgery. Further research could explore whether this effect is found in all religions, because this study examined religiousness, not a particular religion per se. The role of religious beliefs and values on shaping attitudes to cosmetic surgery deserves greater research attention.

ACKNOWLEDGEMENTS: The authors are very grateful to Dr Viren Swami for his help and advice on all aspects of this article.

14. Didie E, Sarwer D. Factors that influence the decision to undergo cosmetic breast augmentation surgery. J Women's Health 2003;12:241-53

15. Schofield M, Hussain R, Loxton D, Miller Z. Psychological and health behavioural covariates of cosmetic surgery. J Health Psychol 2002;7:445-457.

16. Ozgur F, Tuncali D, Gursu G. Life satisfaction, self-esteem, and body image. Aesthetic Plast Surg 1998;22:412-19.

17. Ching S, Thoma A, McCabe R, Antony M. Measuring outcomes in aesthetic surgery. Plast Reconstr Surg 2003;111:468-80.

18. Markey C, Markey P. Correlates of young women's interest in obtaining cosmetic surgery. Sex Roles 2009;61:158-66.

19. Tait $S$. Television and the domestication of cosmetic surgery. Fem Med Stud 2007;7:119-35.

20. Crockett RJ, Pruzinsky T, Persing JA. The influence of plastic surgery 'reality TV' on cosmetic surgery patient expectations and decision making. Plast Reconstr Surg 2007;120:316-24.

21. Cochran JK, Chamlin MB, Beeghley L, Harnden A, Blackwell BS. Religious stability, endogamy, and the effects of personal religiosity on attitudes towards abortion. Sociol Relig 1996;57:291-309.

22. Meisenberg G. Designer babies on tap? Medical students' attitudes to pre-implantation genetic screening. Public Underst Sci 2009;18:149-66.

23. Wenger NS. Physicians' religiosity and end-of-life care attitudes and behaviours. Mt Sinai J Med 2004;5:335-43.

24. Rosenberg M. Society and the adolescent self-image. Princeton: Princeton University Press, 1965.

25. Swami V, Furnham A, Geogiades C, Pang L. Evaluating self and partner physical attractiveness. Body Image 2007;4:97-101.

26. Watkins LM, Johnston L. Screening job applicants: The impact of physical attractiveness and application quality. Int J Select Assess 2000;8:76-84.

27. Dipboye RL, Fromkin HL, Wiback K. Relative importance of applicant sex, attractiveness and scholastic standing in evaluation of job applicant resumes. J Appl Psychol 1975;60:39-43.

28. The Holy Bible. Revised Standard Version. Philadelphia: Westminster, 1952. 